\title{
ACHIEVING CAREER SATISFACTION THROUGH FOSTERING INNOVATION: LESSONS FROM THE ENGINEERING PROFESSION IN THE AUSTRALIAN PUBLIC SECTOR
} pages: $7-21$

\author{
WARIT WIPULANUSAT ${ }^{10}$ KRIENGSAK PANUWATWANICH \\ RODNEY A. STEWART ${ }^{(1)}$ JIRAPON SUNKPHO ${ }^{\circ}$ \\ POOMPORN THAMSATITDEJ
}

Sirindhorn International

Institute of Technology, Thammasat University, Thailand ORCID 0000-0002-6303-9485

Corresponding author: e-mail: kriengsak@siit.tu.ac.th

Warit Wipulanusat

Logistics and Business Analytics Center of Excellence Walailak University, Thailand ORCID 0000-0003-1006-6540

Rodney A. Stewart

Griffith University, Australia ORCID 0000-0002-6013-3505

Jirapon Sunkpho

Thammasat University, Thailand ORCID 0000-0002-5561-2173

Poomporn Thamsatitdej

Thammasat University, Thailand ORCID 0000-0001-5496-4612

\section{INTRODUCTION}

Australian federal departments employ engineers to perform in-house engineering functions, tasks, and projects; to plan, develop, and maintain public works and environmental programmes; to maintain the mis- sion and services legislatively mandated and to manage and oversee work contracted to private engineering firms. Administrative reforms have had significant consequences on the number of engineers in the Australian Public Service (APS). Engineers have been

Wipulanusat, W., Panuwatwanich, K., Stewart, R. A., Sunkpho, J., \& Thamsatitdej, P. (2021). Achieving career satisfaction through fostering innovation: lessons from the engineering profession in the Australian public sector. Engineering Management in Production and Services, 13(4), 7-21. doi: 10.2478/emj-2021-0028 
impacted by these reforms, including privatisation, competition policy, contracting out, and commercialisation. Evidence indicates a decline of between 20 and 50 per cent in the number of professional engineers in the Commonwealth, State, and local government public sectors between 1990 and 1999 (Engineer Australia, 2012). Yates (2001) predicted that if the rate of decline in the number of APS engineers continued unchanged, then by the year 2008, the shortage of engineering professionals would become a critical problem for government agencies. A decade later, this prediction was realised, and most federal departments faced a shortage of engineering professionals. For example, in 2010, engineers were among the top four professions in which public services had the most problems recruiting new graduates and retaining existing employees (Engineer Australia, 2012; Yates, 2012). According to the State of the Service Report 2012-2013, the predominant occupational groups where skill shortages were reported were engineering and technical, accounting and finance, as well as ICT occupations. More than 40 per cent of the engineers who worked in these occupations indicated their intention to leave their agencies within 12 months (Australian Public Service Commission, 2013). The main reason reported regarding the decision to leave their agency was a lack of future career opportunities. In the survey of APS engineers who had indicated they would leave their agency in the next two years, one of the most common departure reasons was a lack of chance to participate in innovative projects (Yates, 2012). From 2015 to 2019, an engineer shortage is still a critical obstacle in which the number of job vacancies for engineers always increases (Lester, 2019). The federal government needs to implement innovation policies to recognise engineers' significant role in turning creative ideas into innovative initiatives.

Within an organisation, a manifestation of sociopsychological phenomena, in the form of "climate", acts as a critical determinant of employee motivation and behaviour and drives the innovation process (Wipulanusat, Panuwatwanich, \& Stewart, 2018). More specifically, several research studies have attempted to investigate the extent to which climate for innovation, consisting of leadership and organisational culture, can act as either a stimulant or an impediment to creativity and innovation (Demircioglu \& Berman, 2019; Panuwatwanich, Stewart, \& Mohamed, 2008; Wipulanusat et al., 2020). Understanding these socio-psychological processes provides a practical way to stimulate workplace innovation within the complicated social systems, which, in turn, encourages engineers' career satisfaction in Australian federal departments.

A career is widely regarded as the lifelong sequence of employees' role-related experiences, despite being conventionally acknowledged to be limited to professionals or those promoted through organisational hierarchies (Hall \& Chandler, 2005). Career satisfaction is the positive psychological achievements that employees obtain from their careers' intrinsic and extrinsic facets, including salary, advancement in job rank, feelings of pride, and developmental opportunities (Greenhaus, Parasuraman, \& Wormley, 1990; Nair et al., 2019; Adeniji et al., 2019; Ohunakin et al., 2018; Tobing, 2016). Some researchers have described that employees consider their career progress to be compatible with their own goals, values, and preferences (Barnett \& Bradley, 2007). Career satisfaction is also identified as employees' feelings of satisfaction or dissatisfaction with their entire career (Lounsbury et al., 2008).

Therefore, there are research deficiencies and gaps regarding the influence of socio-psychological factors on organisational outcomes (i.e., workplace innovation and career satisfaction) within the innovation process for engineers in federal departments. This suggestion emphasises the importance of identifying the key factors that impact workplace innovation and investigating successful workplace innovation practices, leading to increased career satisfaction. Such research can provide empirical evidence to support the relationship between these constructs.

Therefore, federal departments should prioritise assessing and enhancing career satisfaction because receptiveness to career satisfaction should be a key metric of public sector performance. Engineers cannot contribute to their departments if organisations do not promote career satisfaction. This paper aims to study which factors lead engineers to more substantial commitment in the APS by correlating innovation climate, workplace innovation, and career satisfaction.

The study presented in this paper considers the concepts of climate for innovation, workplace innovation, and career satisfaction through individual engineering professionals' lens in the APS. The study was limited to Australian federal departments currently facing a shortage and high attrition rate of engineering professionals. This study aims to apply a coherent and comprehensive approach to help engineers increase career satisfaction, which could help attract and retain the engineering workforce in the APS. 


\section{LITERATURE REVIEW}

\subsection{Conceptual MOdel}

The main objective of this paper is to understand the innovation-conducive conditions and processes within the public sector. Researchers have long studied the relationship between organisational attributes, the organisation's propensity to innovate, and organisational outcomes. It is essential to focus on organisational attributes because they provide practical implications that can be applied for improving the organisational outcome. Socio-psychological constructs (consisting of leadership for innovation and ambidextrous culture for innovation) can be expressed in the form of a climate for innovation, which will improve workplace innovation and career satisfaction in public sectors.

Leadership for Innovation (LFI) is the extent to which leaders are willing to take risks on new initiatives and adopt novel perspectives. Innovative leadership is considered to be present in leaders, having behaviour geared towards applying creativity in innovative projects within the work context (Karia \& Abu Hassan Asaari Muhammad, 2019). Leaders play an important role in developing the process, structures, and climate for an organisation to become innovative and to motivate team expectations toward innovations (Chan, Liu, \& Fellows, 2014; Oke, Munshi, \& Walumbwa, 2009; Orazi, Turrini, \& Valotti, 2013).

Ambidextrous Culture for Innovation (ACI) is defined as an organisation's shared norms, beliefs, assumptions, and fundamental values to establish and maintain a balance of exploration activities and exploitation activities to facilitate innovation in the work environment and reflect innovative practices, procedures, policies, and structures (Kim \& Yoon, 2015; Solís \& Mora-Esquivel, 2019; Wipulanusat, Panuwatwanich, \& Stewart, 2017). The ACI construct incorporates two dimensions: innovative culture (ACI1) and performance-oriented culture (ACI2).

Workplace Innovation (WIT) is the generating force by an individual or a team of individuals changing how organisations manage, organise, and deploy people and technology. It means implementing new interventions and supportive technologies into the workplace (Pot, 2011; Totterdill \& Exton, 2014). Workplace innovation introduces new forms of work and combines structural and cultural practices, enabling employee participation, ultimately enhancing work quality and organisational performance (Carranza, Garcia, \& Sanchez, 2020). WIT construct consists of two dimensions: individual creativity (WIT1) and team innovation (WIT2).

Career Satisfaction (CSF) means employees' affective reaction in satisfaction with their entire career (Dubbelt, Demerouti, \& Rispens, 2019). It also measures employees' psychological accomplishments on their skills and abilities in their career from the intrinsic and extrinsic aspects of their careers, including salary, promotion, honour, and career path (Barnett \& Bradley, 2007; Demircioglu, 2018; Lounsbury et al., 2008). The CSF construct is composed of two dimensions: meaningful work (CSF1) and reward and recognition (CSF2).

\subsection{HYPOTHESIS DEVELOPMENT}

Extensive researches have studied the relationship between leader, culture, innovation, and career satisfaction. Kim and Chang (2009) performed a survey to assess the capability for innovation throughout the Korean central government's 46 ministries. According to the findings, management style, innovative culture, performance-based incentives, and knowledge management appeared to boost governmental organisations' ability to innovate. McAdam, Moffett, Hazlett, and Shevlin (2010) applied structural equation modelling to examine 395 SMEs in the UK, which presented the results that innovation leadership and innovative culture positively impact innovation implementation. A study of innovative behaviour in federal agencies in the United States (US) by Fernandez and Pitts (2011) revealed that front-line employees were motivated to generate bottom-up innovation by reward and recognition, training and development, employee empowerment, and participation in decision-making.

Kim and Lee (2009) also examined the impact of the management ability for innovation adoption and implementation in the Korean Government. They claimed that adopting and implementing innovative projects necessitated full-scale management capacity, including innovative leadership, a quality workforce, procedures and structures conducive to inventive behaviour, and the reduction of adverse external influences. The most crucial aspect in encouraging the dynamics of governmental innovation is innovative leadership, which is defined by effective change management, leadership commitment, and workforce stability. Parry and Proctor-Thomson (2002) carried out a nationwide leadership survey to examine 


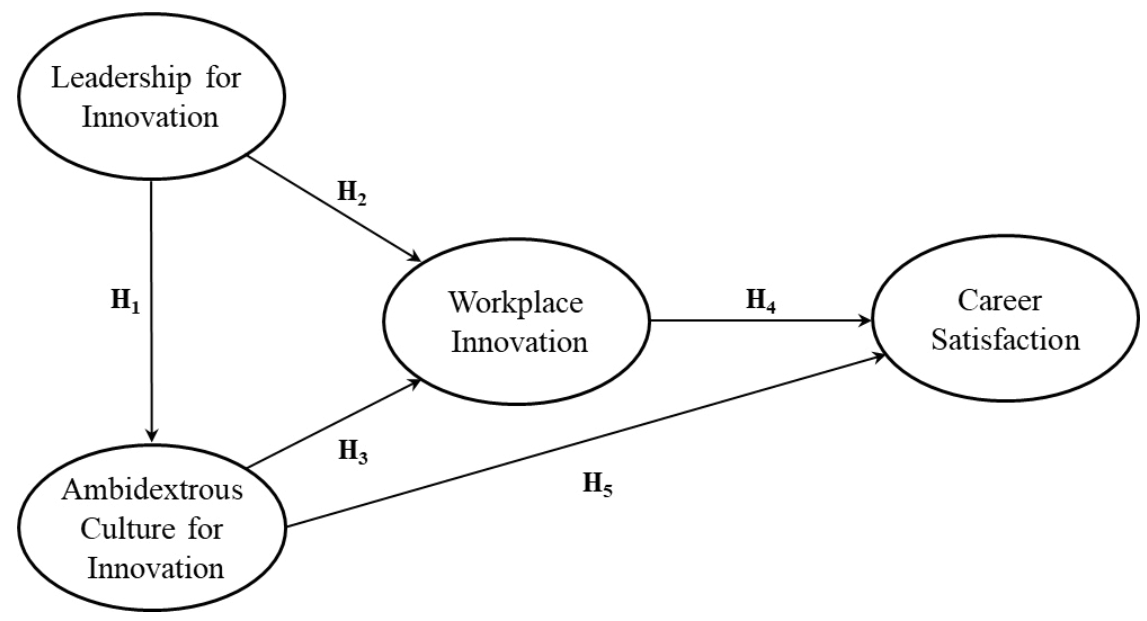

Fig. 1. Conceptual model

organisational aspects associated with innovation in the New Zealand public sector. This study employed structural equation modelling to explore hypotheses on the relationships between leadership manifestations, organisational culture, and innovation. The impacts of transformational leadership on organisational outcomes were shown to be supported by its influence on facilitating a transformational culture and transactional culture on the climate for innovation. A Taiwanese study confirmed that organisations have to focus on workplace innovation to derive the optimum R\&D employee's career satisfaction (Cheng, Lai, \& Wu, 2010). In the Australian public sector context, Demircioglu and Berman (2019) revealed that innovation culture encourages creativity and innovation in the workplace and increases career satisfaction, thereby decreasing employee turnover intention.

It can be seen that the majority of the variables discussed above correspond to both socio-psychological constructs underlying the climate for innovation, consisting of leadership for innovation and ambidextrous culture for innovation. Workplace innovation is also related to career satisfaction. Also, ambidextrous culture for innovation can further increase career satisfaction. The following research question is formulated: What is the interaction between leadership for innovation, ambidextrous culture for innovation, workplace innovation in enhancing career satisfaction? Therefore, as shown in Fig. 1, a conceptual model has been proposed to empirically investigate the hypotheses between these constructs, which will provide an answer to the research question. The test results can provide critical contributions to the litera- ture concerning the factors affecting innovation outcomes in public sectors.

H1: Leadership for innovation positively impacts ambidextrous culture for innovation.

H2: Leadership for innovation is positively related to workplace innovation.

H3: Ambidextrous culture for innovation positively influences workplace innovation.

H4: Workplace innovation is positively associated with career satisfaction.

H5: Ambidextrous culture for innovation positively impacts career satisfaction.

\subsection{DATA AND MEASUREMENT}

Data were derived from the Australian Public Service Commission (APSC) dataset. The 2014 APSC dataset was used because this is the last year that APSC revealed the occupation of the respondents. The sample for this study was drawn from engineering professionals. There were 3125 valid samples of engineers in federal departments. The majority of respondents were male $(86 \%)$ and worked in an operational role $(68 \%)$. Concerning education, $78 \%$ graduated with a bachelor's degree. Most of them (73 $\%)$ had more than five years of tenure. In conclusion, the demographic profile of respondents represented the distribution of the population.

The questions in the survey were self-reported questionnaires using a five-point Likert scale. These questions were grouped according to the definition of each construct. Leadership for innovation was measured using eleven items (e.g., "My supervisor encourages people to find new ways of doing work"; $\alpha=.95$ ). 
Ambidextrous culture for innovation was measured with eleven items (e.g., "My agency emphasises innovation"; $\alpha=.89$ ). Workplace innovation consisted of seven survey items (e.g., "I would be supported if I tried a new idea"; $\alpha=.85$ ). Finally, eight survey items were used to represent career satisfaction (e.g., "I enjoy the work in my current job"; $\alpha=.85)$.

\section{MethodolOgY}

The present study adopted an integrated approach combining structural equation modelling (SEM) and Bayesian network (BN). SEM provides an advantage over traditional regression analysis because it simultaneously estimates covariances between measured variables while estimating the regression paths of multiple dependent variables (van Horn et al., 2016). BN is an increasingly popular data-mining technique due to its state-of-the-art representation of probabilistic knowledge. BN represents graphical interaction between causes and effects and allows for modelling the level of uncertainty, which can change with new evidence (Boehmke et al., 2016; de Oliveira, Dalla Valentina, \& Possamai, 2012). BN's unique nature and merit provide a visual tool for a decision support model for solving problems relating to complexity, uncertainty, and probabilistic reasoning.

While both methods are crucial for quantitative analysis, they have different characteristics that need to be considered. First, as SEM is theory-based, it quantifies and evaluates assumed causal relationships using statistical data, whereas $\mathrm{BN}$ is a graphic model based on probability theory (Anderson \& Vastag, 2004; Gupta \& Kim, 2008). Second, SEM is appropriate for empirical validation based on theoretical causal relationships, whereas $\mathrm{BN}$ can be data-driven and construct causal maps based on background knowledge and historical data (Kayakutlu et al., 2017; Wu, 2010). Third, $B N$ is appropriate when training with new data because it does not affect a model's structure, thereby supporting a useful scenario analysis. Simultaneously, SEM is unsuitable for training with new data because it may change the casual relationship structure (Ekici \& Ekici, 2016; Gupta \& Kim, 2008). Fourth, SEM is more suitable for linear relationships because although it can accommodate non-linear relationships, the process requires complex coding and results in output which is complicated and difficult to interpret (Anderson et al., 2004). In contrast, BN can easily model non-linear relationships, thus evaluating the impact of changes in the model (Anderson \& Vastag,
2004; Gupta \& Kim, 2008). Fifth, SEM is parametric in distribution and function, so it is necessary to satisfy univariate and multivariate normality and statistical assumptions, as well as to justify theoretical evidence (Cardenas, Voordijk, \& Dewulf, 2017). BN, being nonparametric, does not need to follow the specific function form and strict statistical assumptions because the computational process is the calculation of the probability distribution of the variables in the model (Ekici \& Ekici, 2016). Sixth, SEM can only predict dependent variables, provided the independent variables are specified, whereas $\mathrm{BN}$ can calculate the probabilities for both dependent and independent variables (Lauría \& Duchessi, 2006). Seventh, SEM relationships, presented in the dimensionless regression metric in terms of standardised regression weights, have no empirical metric making them appropriate because the latent constructs have not been measured (Anderson \& Vastag, 2004). However, $\mathrm{BN}$ provides descriptions in terms of probabilities, which especially suit prediction and diagnosis by changing the probability of variables, so they are more comfortable for decision-makers to understand (Blodgett \& Anderson, 2000; Ekici \& Ekici, 2016). Finally, SEM is the appropriate method for describing theoretical constructs with no requirement for probabilistic inference to observable variables. If the prediction and diagnostics of observed variables is the required objective, then the $\mathrm{BN}$ should be adopted (Andersen \& Kragh, 2015).

Many researchers (e.g., Chan et al., 2014; Panuwatwanich et al., 2008; Sarros, Cooper, \& Santora, 2008; Wipulanusat et al., 2018) have conducted SEM to investigate conceptual models within the innovation research field. The SEM provides an empirically validated model based on innovation theory, which is appropriate for latent variable modelling. The linking of SEM to BN is achieved by determining the scores of the latent factors used in SEM, which can be utilised as raw data for latent variable modelling in $\mathrm{BN}$ based on the assumptions under which BN represents causality (Gupta \& Kim, 2008). However, there is a lack of research examining the cause-and-effect relationships between these variables and the innovation outcomes. Therefore, this paper presented empirical research, which is necessary to increase the theoretical understanding of how innovation outcomes can be enhanced. In an attempt to shed additional light on this issue, the study developed a hybrid SEM-BN approach as a decision support framework for innovation management. This paper adopts an integrated approach that combines novel methods based on empirical validation of SEM and prediction ability of 
BN (Gupta \& Kim, 2008; Hsu et al., 2009; Li et al., 2018). This study combined SEM with BN to study the influence of climate for innovation, consisting of leadership for innovation and ambidextrous culture for innovation, on workplace innovation and career satisfaction.

\section{STRUCTURAL EQUATION MODEL}

SEM is a statistical technique used to assess the causal relationships among model constructs, which also explains the covariance among a set of variables. In particular, SEM allows a simulant analysis that incorporates the observed (measured) and unobserved variables (latent/constructs), independent and dependent variables, in a graphical language, which is a powerful approach to present complicated relationships and related estimated parameters (Hair et al., 2010). The main objective of SEM is to test how a model derived from theory has a close fit to the sample data (Hair et al., 2010). SEM analyses are typically conducted in two steps: validating a measurement model and fitting a structural model (Byrne, 2010; Hair et al., 2010). A measurement model, achieved through confirmatory factor analysis (CFA), examines the loading relationships between latent variables and their corresponding observable variables, while structural models examine the hypotheses relationships among the unobserved variables through path analysis.

The measurement model consists of two equations, with terms defined as follows (Iacobucci, 2009; Wipulanusat, Sunkpho, \& Stewart, 2021):

$$
\begin{gathered}
x=\Lambda_{x} \xi+\delta \\
y=\Lambda_{y} \eta+\varepsilon
\end{gathered}
$$

Where:

$x$ represents a column vector of exogenous, or independent, variables;

$\Lambda_{x}$ represents the correlation matrix of exogenous factor loadings of $x$ on $\xi$;

$\xi$ represents a vector of the independent latent variables, exogenous constructs;

$\delta$ represents a column of measurement errors in $x$;

$y$ represents a column vector of endogenous variables;

$\Lambda_{y}$ represents the matrix of endogenous factor loadings of $y$ on $\eta$;

$\eta$ represents a vector of latent dependent, or endogenous, constructs; $\varepsilon$ represents a vector of measurement errors in $y$.

The structural model is an expression that is written by the following equation (Iacobucci, 2009; Wipulanusat et al., 2021):

$$
\eta=\beta \eta+\Gamma \xi+\zeta
$$

Where:

$\beta$ represents a matrix of direct effects between endogenous variables;

$\Gamma$ represents a matrix of regression effects of the exogenous variables;

$\zeta$ represents a column vector of the error terms.

The Analysis of Moment Structures (AMOS) version 22 was used to evaluate quantitative data using SEM, allowing the data from the SPSS analysis set to be automatically used in the AMOS computation (Byrne, 2010). Furthermore, AMOS visuals combine a simple graphical user interface with a robust computing algorithm, making its use appealing and providing calculations of the most critical parameters. The complete details of model development and assessment were explained in Wipulanusat et al. (2018). The structural model demonstrated an acceptable fit to observed data $\left(\chi^{2}=\right.$ $300.89, d f=15, \mathrm{GFI}=0.98, \mathrm{CFI}=0.98, \mathrm{TLI}=0.95$, IFI $=0.98, \mathrm{SRMR}=0.02$, and RMSEA $=0.08$ ), as shown in Fig. 2.

Following the conceptual model's satisfactory results, a model comparison should be conducted to confirm the final structural model to explain the data best. The model comparison aims at evaluating the model fit and comparing the fit of competing and theoretically plausible models (Byrne, 2010). This study employs a hierarchical analysis to compare the conceptual model with its nested models. A nested model refers to a subset of an original conceptual model, which has a specific link being added (model building) or removed (model trimming). This paper used the model trimming for the nested model, which was done by removing the path from $\mathrm{ACI} \rightarrow \mathrm{CSF}$.

For the model comparison, parsimony fit measures such as the Akaike Information Criterion (AIC) is suitable for model comparison since they evaluate parsimony and fit (Arbuckle, 2013). AIC calculates predictive fit indices and illustrates how well a model could be supposed to fit sample data from the same population (Weston \& Paul, 2006). AIC is mainly useful for selecting between the comparison of models rather than providing whether a single model fits the data. AIC is not appropriate for determining how well 


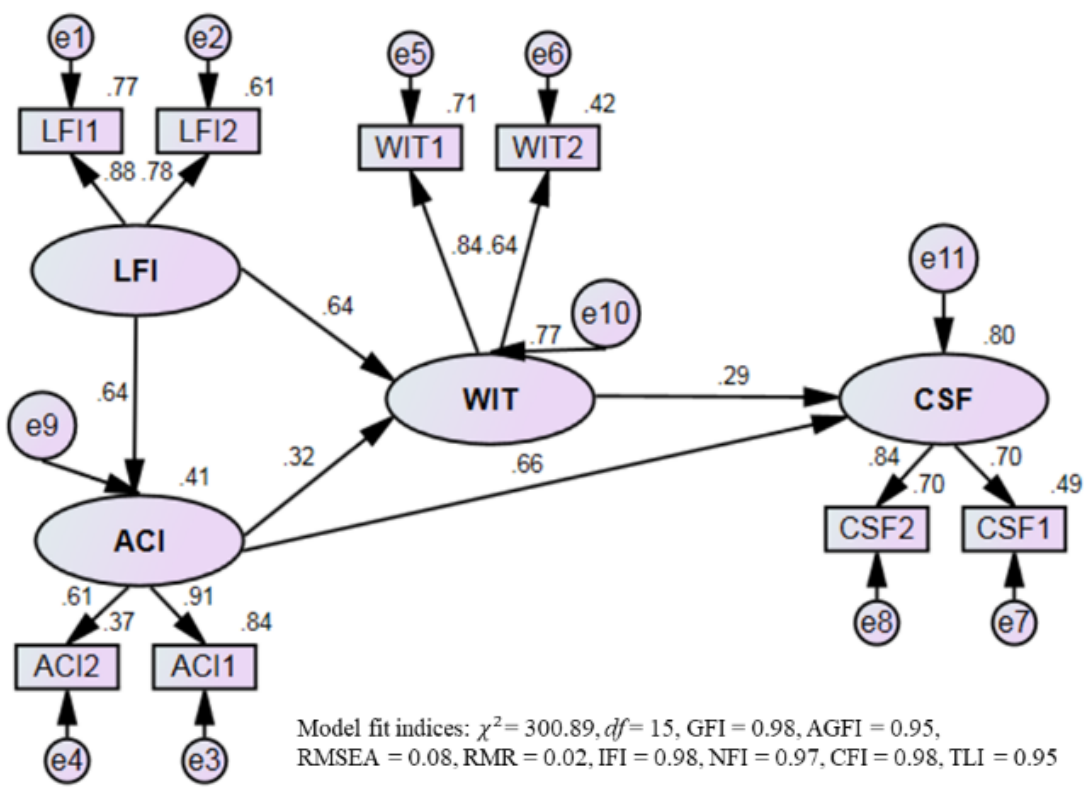

Fig. 2. Structural model

Source: (Wipulanusat et al., 2018).

a single model fits the data, but it is commonly used to select amongst models. The model which has the lowest AIC is considered to have a better fit.

As shown in Tab. 1, some fit indices in the nested model did not meet acceptable levels (i.e., AGFI = 0.89 and RMSEA $=0.11)$. In the case of the nested model, its AIC was 690.06, while the AIC value for the conceptual model was 342.90. The smaller AIC value demonstrated better parsimony for the conceptual model and a better fit than the nested model (Arbuckle, 2013). These AIC results supported the conceptual model as a parsimonious model and the preferred model to exemplify the survey data. Therefore, the conceptual model (Fig. 1) was confirmed as the structural model.

The structural model has provided fundamental background knowledge concerning how the climate for innovation is conceptualised, and the specific factors related to workplace innovation and career satisfaction. Table 2 presents the standardised coefficients from the structural model. Leadership for innovation was defined as an exogenous factor $(\gamma)$. The remaining constructs were considered as endogenous factors $(\beta)$. Leadership for innovation has a significant impact on ambidextrous culture for innovation $(0.64$, $\mathrm{p}<0.001)$ and workplace innovation $(0.64, \mathrm{p}<0.001)$. Ambidextrous culture for innovation has an influence on workplace innovation $(0.32, \mathrm{p}<0.001)$. Workplace innovation is also related to career satisfaction
$(0.29, \mathrm{p}<0.001)$. Also, ambidextrous culture for innovation is a crucial antecedent for career satisfaction $(0.66, \mathrm{p}<0.001)$. Therefore, the structural model has been presented in this study to reveal the relationships between these constructs empirically.

Tab. 1. Comparison of the fit indices

\begin{tabular}{|l|r|r|}
\hline \multicolumn{1}{|c|}{ FIT INDICES } & \multicolumn{1}{c|}{ NeSTED MOdeL } & \multicolumn{2}{c|}{$\begin{array}{c}\text { CONCEPTUAL } \\
\text { MODEL }\end{array}$} \\
\hline$\chi^{2}$ & 650.06 & 300.90 \\
\hline$d f$ & 16 & 15 \\
\hline GFI & 0.95 & 0.98 \\
\hline AGFI & 0.89 & 0.95 \\
\hline CFI & 0.95 & 0.98 \\
\hline RMSEA & 0.11 & 0.08 \\
\hline AIC & 690.06 & 342.90 \\
\hline
\end{tabular}

Tab. 2. Structural equations

\begin{tabular}{|c|c|c|}
\hline PATHS & STRUCTURAL EQUATIONS & Coefficient \\
\hline $\mathrm{LFI} \rightarrow \mathrm{ACl}$ & $Z_{A C I}=0.64\left(Z_{L F I}\right)$ & $\nu=0.64$ \\
\hline $\mathrm{LFI} \rightarrow \mathrm{WIT}$ & $Z_{W I T}=0.64\left(Z_{L F I}\right)+0.32\left(Z_{A C I}\right)$ & $\nu=0.64$ \\
\hline $\mathrm{ACl} \rightarrow \mathrm{WIT}$ & & $B=0.32$ \\
\hline $\mathrm{ACl} \rightarrow \mathrm{CSF}$ & $Z_{C S F}=0.66\left(Z_{A C I}\right)+0.29\left(Z_{\text {WIT }}\right)$ & $B=0.66$ \\
\hline (WIT $\rightarrow$ CSF & & $B=0.29$ \\
\hline
\end{tabular}




\section{BAYESIAN NETWORKS}

The structural model was subsequently adopted as a causal map to develop the directed acyclic graph (DAG) consisting of connected nodes representing important domain variables and arcs representing causal relationships between nodes. The $\mathrm{BN}$ uses a conditional probability table (CPT) to explain the probability of each node and describes the strength of the causal relationship between these nodes (Wipulanusat et al., 2020). There are $\mathrm{N}$ variables in the DAG. Nodes are variables presenting as $\mathrm{X}_{1}, \mathrm{X}_{2}, \ldots, \mathrm{X}_{\mathrm{n}}$. The set of parent nodes with an arc to $X_{i}$ can be denoted by $\pi_{i}$, while $\mathrm{P}\left(\mathrm{X}_{\mathrm{i}} \mid \pi_{\mathrm{i}}\right)$ represents the conditional probability distribution (Wipulanusat, Panuwatwanich, Stewart, Parnphumeesup, \& Sunkpho, 2020). The joint probability of the $\mathrm{BN}$ is referred to as the following formula:

$P\left(X_{1}, X_{2}, \ldots, X_{n}\right)=\prod_{i=1}^{N} P\left(X_{i} \mid \pi_{i}\right)$

The BN was developed based on an empirically tested structural model. The first step involved constructing a causal map, also known as the DAG, developed by analysing the sequence of constructs in the structural model. Developing the DAG started with the between-construct relationships from the theoretically validated structural model. Leadership for innovation (LFI) was confirmed to be a common cause of ambidextrous culture for innovation (ACI) and workplace innovation (WIT). Furthermore, culture for innovation (ACI) was found to be the direct cause of workplace innovation (WIT) and career satisfaction (CSF). This relationship between A and B is generated from a common cause $\mathrm{C}$, represented as $\mathrm{A} \leftarrow \mathrm{C} \rightarrow \mathrm{B}$. The causal relationships were classified as follows: $\mathrm{ACI} \leftarrow \mathrm{LFI} \rightarrow \mathrm{WIT}$ and $\mathrm{WIT} \leftarrow \mathrm{ACI} \rightarrow \mathrm{CSF}$. Once all causal relationships between constructs have been established, the DAG was developed based on an empirically validated model, as depicted in Fig. 3. Data entry for each node was the average value of the relevant questionnaire items of the construct. Based on the chance of occurrence, each node was discretised by categorising a five-point scale into three states: [1-2.5] as low, [2.5-4] as medium, and [4-5] as high. Netica software was used to construct the BN. The DAG and corresponding data were entered into the software for the parameter learning process.

In the next step, the counting algorithm was adopted for quantifying the CPT of each node. This is because it is the most straightforward method and a true Bayesian learning algorithm. When the CPTs were learned, the belief bars were used to present all node probabilities in the BN, as shown in Fig. 4. For example, the belief on the leadership for innovation node indicates that the medium state equals 59.5 per cent, which can be written as $\mathrm{P}$ (leadership for innovation $=$ medium $)=0.595$. The $\mathrm{BN}$ consists of four nodes and five causal relationships. In this situation, a mean LFI (59.5 per cent), a median ACI (70.5 per cent), and a median WIT (73 per cent) are likely to occur. These three nodes lead to the medium CSF node (70 per cent).

The mean value and standard deviation are displayed at the bottom of each node. The mean value of the career satisfaction node, for instance, is 3.28. Thus, there is significant room for development through increasing career satisfaction of engineers in the APS.

The first scenario of improvement emerges when there are the odds of 100 per cent occurrence of high leadership for innovation together with evidence of ambidextrous culture for innovation, as shown in Fig. 5. The probability of high career satisfaction rose from 19.3 to 53.0 per cent, representing an increase in the mean value of career satisfaction by 18.3 per cent $(3.28 \rightarrow 3.88)$.

In this scenario, innovation leaders can inspire employees to be innovative by fostering an innovation culture. Leadership for innovation, also known as innovation leadership, represents the ability and actions that develop and promote an organisational climate in which individuals can participate in innovation activities to acquire essential ideas. Innovation leadership is concerned with establishing, leading, and managing innovation processes and encouraging effective employee involvement in the process. A culture for innovation is an organisational culture that genuinely values and encourages innovation, allowing people to make it happen. A strong innovation culture is the prime mover that enables the organisation to improve continually, progress, and innovate.

Consequently, the $\mathrm{BN}$ allows entering evidence for each node and observing the change in other nodes' posterior probabilities. The inference was conducted to determine how much the mean values of related factors need to be improved for achieving the high state of career satisfaction. In this scenario, the career satisfaction node is assumed as the high state, as shown in Fig. 6.

Engineers' career satisfaction is crucial, considering that engineer shortage remains a critical challenge as the number of vacant jobs for engineers continues 


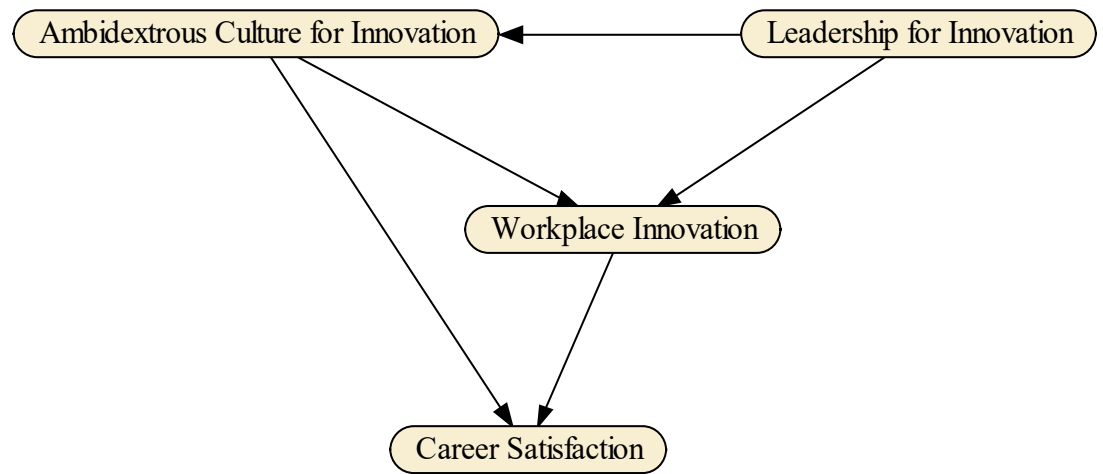

Fig. 3. Directed acyclic graph

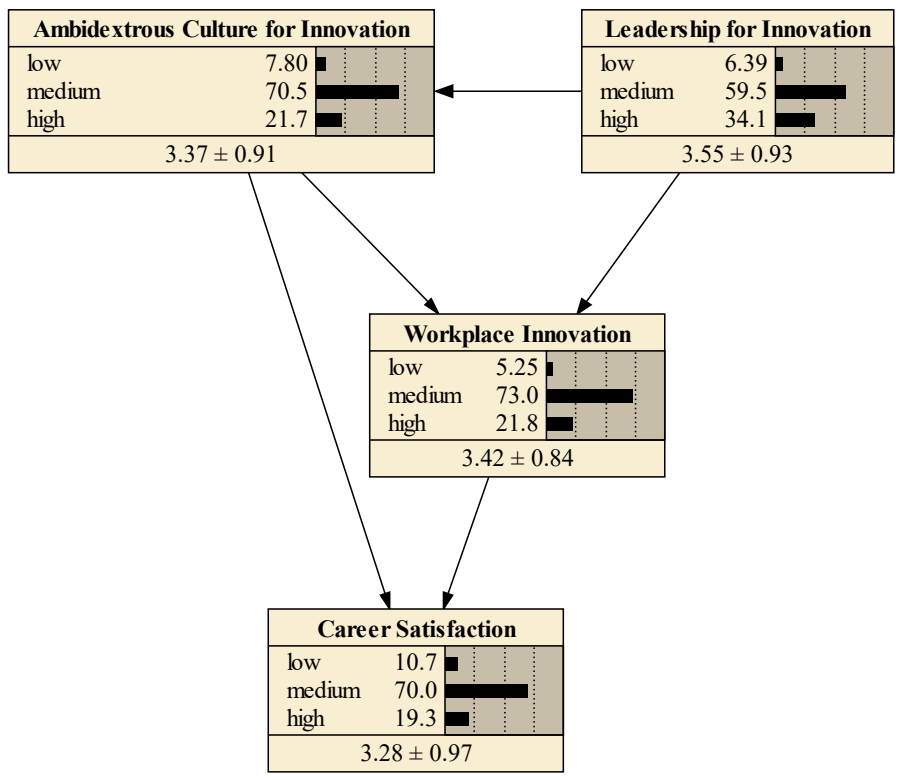

Fig. 4. Bayesian network

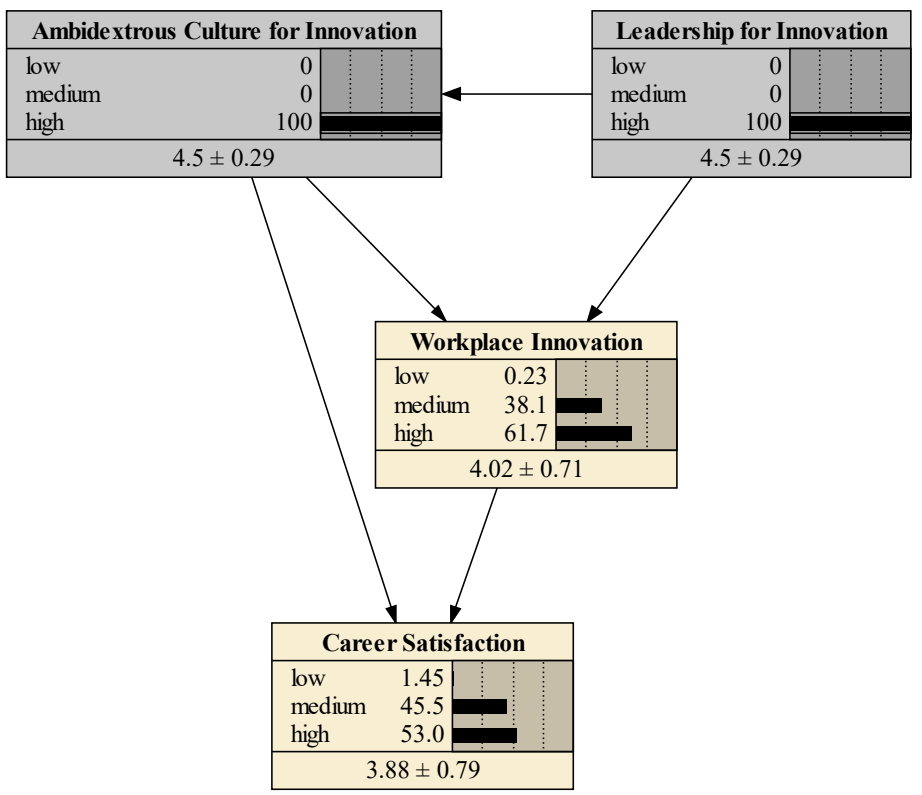

Fig. 5. Effect of high LFI and High ACl 


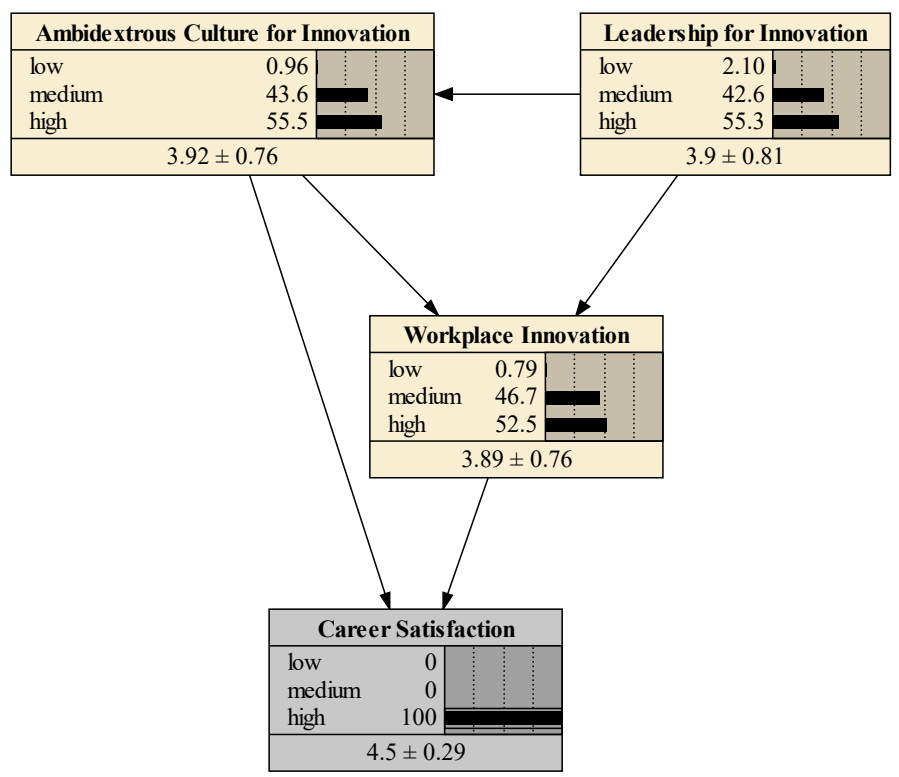

Fig. 6. Best scenario for career satisfaction

to rise in the APS. Improving engineers' career satisfaction could make engineering a more appealing profession. The APS should boost their engineers' intrinsic motivation to enhance their career satisfaction (Bielefeldt \& Canney, 2019). Intrinsic motivation is based on the enjoyment of the engineering job itself. According to the job characteristics model, the optimal design of occupations is the most effective technique to motivate engineers. Job features such as independence, skill diversity, task uniqueness, task relevance, and assessment should be emphasised if work-related motivation needs to be promoted (García-Chas, Neira-Fontela, \& Varela-Neira, 2016).

As presented in Tab. 3, increases in the change rates of the mean value of related factors were reported as part of the results. There was a slight change rate on the mean value of leadership for innovation ( 9.86 per cent), while ambidextrous culture for innovation needed to be increased considerably (16.32 per cent). There was a moderate increase in workplace innovation (13.74 per cent). Although this optimistic scenario may be challenging to implement, increasing the mean values of factors from 9.86 to 16.32 per cent should be considered to achieve a high career satisfaction of engineers in the APS.

Once the $\mathrm{BN}$ is constructed, the next step is to evaluate the model's ability for predictive correctness. To assess the performance of the $\mathrm{BN}$, a confusion matrix was adopted for this study. The confusion matrix was used to determine classification accuracy from an error rate. It was developed with columns corresponding to the predicted values from the $\mathrm{BN}$ and rows representing the actual values from respondents' answers. To evaluate predictive power, 100 cases from the spreadsheet were randomly selected for analysis. As the BN's ultimate aim was to develop strategies for promoting career satisfaction, this node was specified as an output for calculating the confusion matrix. Table 4 presents the results of the confusion matrix developed to determine the robustness of the $\mathrm{BN}$.

As evident from the confusion matrix, the total error rate was equal to 24 per cent, which indicated the model was 76 per cent accurate in its predictions for the career satisfaction node. The error rate of the $\mathrm{BN}$ indicated that the developed network had an

Tab. 3. Prior and the posterior mean value of factors

\begin{tabular}{|l|r|r|r|}
\hline \multirow{2}{*}{ Factors } & \multicolumn{2}{|c|}{ Mean Value } & \multirow{2}{*}{ Change Rate (\%) } \\
\cline { 2 - 3 } & \multicolumn{1}{|c|}{ Prior } & \multicolumn{1}{c|}{ Posterior } & \\
\hline LFI & 3.55 & 3.90 & 9.86 \\
\hline ACI & 3.37 & 3.92 & 16.32 \\
\hline WIT & 3.42 & 3.89 & 13.74 \\
\hline
\end{tabular}

Tab. 4. Confusion matrix for the robustness test

\begin{tabular}{|c|c|c|c|}
\hline \multirow{2}{*}{$\begin{array}{l}\text { ACTUAL FROM } \\
\text { RESPONSES }\end{array}$} & \multicolumn{3}{|c|}{ PREDICTED FROM THE BN } \\
\hline & Low & Medium & HIGH \\
\hline Low & 2 & 5 & 1 \\
\hline Medium & 1 & 68 & 4 \\
\hline High & 0 & 13 & 6 \\
\hline
\end{tabular}


acceptable level of accuracy. As part of the BN process, scoring rules were also calculated to provide an assessment of the degree of fit over a set of variables. These scoring rules comprise logarithmic loss, quadratic loss, and spherical payoff. Of the three scoring rules, the logarithmic loss is the one that calculates the value independently of the chance of the output that literally occurs (Dlamini, 2010). The logarithmic loss ranges between zero and infinity - the closer to zero, the better the model's goodness of fit. The quadratic loss varies between zero and two, where a lower value corresponds to better execution of the $\mathrm{BN}$. Finally, the spherical payoff has a value between zero and one, indicating a perfect fit between the model and the data (Fuster-Parra et al., 2014; Mohammad-

Logarithmic loss $=M O A C\left[-\log \left(P_{c}\right)\right]$

Quadratic loss $=$ MOAC $\left[1-2 P_{c}+\sum_{j=1}^{n} P_{j}^{2}\right]$

Spherical payoff $=M O A C \cdot\left[\frac{P_{c}}{\sqrt{\sum_{j=1}^{n} P_{j}^{2}}}\right]$

fam et al., 2017). These indices are calculated by the following equations (Marcot, 2012):

Where MOAC represents an abbreviation for the mean over all cases (i.e., all cases in which the case file contains a value for the node in question). $\mathrm{P}_{-} \mathrm{c}$ stands for the predicted probability for the correct state, $P_{-} j$ stands for the predicted probability for state $j$, and $n$ is the total number of states (Chanpariyavatevong et al., 2021).

The logarithmic loss and quadratic loss scores for the $\mathrm{BN}$ in this study were 0.6058 and 0.3454 , respectively, while the spherical payoff was 0.8068 . These scoring rule results indicated a reasonable degree of fit for the BN. No previous studies conducted in the area of innovation management report on these indices. However, they correspond to the indices presented by previous studies conducted in environmental and safety areas (Dlamini, 2010; Fuster-Parra et al., 2014; Mohammadfam et al., 2017). Thus, it can be concluded that the $\mathrm{BN}$ provided acceptable predictive abilities to examine the relationships between different factors in the innovation process for the APS.

\section{DISCUSSION AND CONCLUSIONS}

While it is crucial to promote the career satisfaction of engineering professions in public sectors, little comprehensive research has been carried out to examine the innovation process within governmental agencies. This paper presents an integrating approach to link an empirically validated model based on structural equation modelling (SEM) with the Bayesian network (BN) method to understand the interplay between salient organisational constructs and their ability to influence career satisfaction in the Australian Public Service (APS).

According to the $\mathrm{BN}$ results, the ambidextrous culture for innovation was found to be the most crucial factor for increasing career satisfaction, in line with the previous research using a structural model conducted by Wipulanusat et al. (2018). Such a Hybrid SEM-BN approach can be used as a framework to devise strategies to improve engineers' career satisfaction in the public sectors. This paper proposes managerial implications for the commonwealth department to increase the career satisfaction of its engineers. The first managerial implication is that leaders should maintain a balance between an innovative and performance-oriented culture in their organisations. Innovative culture plays a significant role in improving innovation conditions, and the engineers can act as agents for innovation (Williamson, Lounsbury, \& Han, 2013; Wipulanusat et al., 2019). Leaders must demonstrate the capacity to recognise the signs of imbalance between both cultures and prepare to restore the delicate balance when essential. Innovative leadership development programmes should also be adopted to prepare leaders involved in innovative initiatives effectively.

The second practical implication is based on developing creativity. Senior managers should provide opportunities for engineers to participate in the innovation process to create, develop, experiment with, and implement innovative solutions. Having the freedom to learn and take necessary risks under considerate guidelines can encourage continuous innovative behaviour in the workplace (Menzel, Aaltio, \& Ulijn, 2007). Commonwealth departments that assign engineers to manage and develop current tasks while providing the engineers with enough innovative capability to predict possible solutions can achieve the transformation to confirm significant results and generate new solutions and production of innovative products, processes, or services, which results in increasing workplace innovation in their organisation. These integrated activities can help the APS functionally complementary achieve the ultimate organisational goal to optimise career satisfaction, which could reduce the turnover rate of these engineers (García-Chas et al., 2016). Because low 
career satisfaction may encourage engineers to change their job in the public sector, pursue a better fit for their values through a transition to work in the private sector, or, eventually, quit the engineer occupation and move into a different career (Bielefeldt \& Canney, 2019).

The third managerial implication is that understanding engineers' career satisfaction is critical since human resources are an agency's most valuable intangible asset. Their attitudes influence organisational performance in the APS. Therefore, federal departments focus on attracting and retaining knowledgeable and well-educated engineers to work in their agencies, which can be achieved by supporting the innovation atmosphere. Public administrators should motivate and support engineers' creativity and design more fulfilling tasks and allow them greater autonomy. They should also explore methods to improve the innovation atmosphere in their agencies by motivating, encouraging, and acknowledging engineers who create innovative ideas and ensuring that agencies recognise the significance of their creativity, even if some of the ideas fail.

The fourth managerial implication is that federal departments, conventionally, are subject to more bureaucratic procedures, have more controls to avoid wrongdoing, and limit risk-taking activities. Public executives are likewise limited in their ability to use financial rewards to reward innovators. According to empirical research, financial rewards do not work effectively in the civil service (Demircioglu \& Berman, 2019). Instead, executives should strive to enhance the innovation climate, promoting engineers' career satisfaction. Public agencies could train project managers to encourage engineers to contribute more ideas and change regulations to support more risktaking initiatives in their projects.

\section{LIMITATION AND FUTURE RESEARCH}

This study has limitations that should be acknowledged. Some scholars argue that causality cannot be ensured by the results of any statistical techniques regardless of the level of complexity (e.g., Bullock, Harlow, \& Mulaik, 1994). Scholars in the field of causal inference and SEM also agree that associations alone do not establish causal relationships (Weston \& Paul, 2006). When a model is assessed and reveals a significant coefficient and model fit, a well-fitting structural model does not and cannot prove causal assumptions (Bollen \& Pearl,
2013). However, the structural model can offer plausible causal relationships as it is proposed that causality can be determined by the underlying theory and research design (Lei \& Wu, 2007). Therefore, this study was conducted by meeting the essential assumptions for causal inference. These assumptions included the data quality, the conformity of the hypothesis compared to theory, and the match between the hypothesis's substantive statement and the applied statistical method.

Future work should further examine the outcome of career satisfaction, such as how career satisfaction is related to career success in the public sector. This is because career satisfaction is a significant predictor of career success, defined as the accumulated positive work and psychological outcomes deriving from one's work experiences (Bretz \& Judge, 1994). Career success has been conceptualised as extrinsic and intrinsic outcomes and is thus measurable using objective and subjective indicators. Objective career success indicates an extrinsic outcome, such as a sequence of official positions, salary changes, and formal structures and titles, all of which are publicly accessible and relatively tangible ( $\mathrm{Ng}$ et al., 2005). In contrast, subjective career success is defined as employees' evaluations of their career progress and accomplishments, prospects for future advancement, development of new skills, and work-life balance relative to their targets and ambitions (Seibert \& Kraimer, 2001).

However, having accomplished objective career success does not necessarily express that employees are satisfied with their careers (Hall \& Chandler, 2005). Researchers have revealed that employees with a higher subjective career success feel happier about their careers relative to their own subjective judgments. Subjective career success demonstrates satisfaction over a long time frame and a wide range of outcomes, such as work-life balance and a sense of purpose (Ng et al., 2005; Seibert \& Kraimer, 2001). Therefore, it is also significant to measure subjective career success as it has implications for employees' psychological well-being, self-managed careers, and their quality of work-life (Peluchette, 1993).

\section{ACKNOWLEDGEMENTS}

The publication of the article for 11th International Conference on Engineering, Project, and Production Management - EPPM2021 was financed in the framework of the contract no. DNK/ SN/465770/2020 by the Ministry of Science and 
Higher Education within the "Excellent Science" programme.

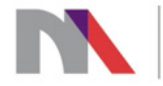

Ministry of Science and Higher Education

Republic of Poland

\section{LITERATURE}

Adeniji, A., Osibanjo, O., Salau, O. P., Falola, H. O., Igbinoba, E., Ohunakin, F., \& Ogueyungbo, O. (2019). Competence model for measuring career development and organisational growth in the health sector. Business: Theory and Practice, 20, 248-258. doi: 10.3846/btp.2019.24

Andersen, P. H., \& Kragh, H. (2015). Exploring boundaryspanning practices among creativity managers. Management Decision, 53(4), 786-808. doi: 10.1108/MD06-2014-0399

Anderson, R. D., Mackoy, R. D., Thompson, V. B., \& Harrell, G. (2004). A Bayesian network estimation of the service-profit chain for transport service satisfaction. Decision Sciences, 35(4), 665-689.

Anderson, R. D., \& Vastag, G. (2004). Causal modeling alternatives in operations research: Overview and application. European Journal of Operational Research, 156(1), 92-109. doi: 10.1016/S0377-2217(02)00904-9

Arbuckle, J. (2013). AMOS 22. User's guide. Chicago, IL: SmallWaters Corporation.

Australian Public Service Commission. (2013). State of the Service Report: State of the Service Series 2012-2013. Canberra, ACT, Australia.

Barnett, B. R., \& Bradley, L. (2007). The impact of organisational support for career development on career satisfaction. Career Development International, 12(7), 617-636. doi: 10.1108/13620430710834396

Bielefeldt, A. R., \& Canney, N. E. (2019). Working engineers' satisfaction with helping people and society through their jobs. European Journal of Engineering Education, 44(6), 939-953. doi: 10.1080/03043797.2018.1476468

Blodgett, J. G., \& Anderson, R. D. (2000). A Bayesian network model of the consumer complaint process. Journal of Service Research, 2(4), 321-338. doi: $10.1177 / 109467050024002$

Boehmke, B. C., Johnson, A. W., White, E. D., Weir, J. D., \& Gallagher, M. A. (2016). Tooth-to-tail impact analysis: Combining econometric modeling and Bayesian networks to assess support cost consequences due to changes in force structure. Journal of Cost Analysis and Parametrics, 9(1), 2-31. doi: 10.1080/1941658X.2016.1155186

Bollen, K. A., \& Pearl, J. (2013). Eight myths about causality and structural equation models. In Handbook of causal analysis for social research (pp. 301-328). Springer.

Bretz, J. R. D., \& Judge, T. A. (1994). Person-organization fit and the theory of work adjustment: Implications for satisfaction, tenure, and career success. Journal of Vocational Behavior, 44(1), 32-54. doi: 10.1006/ jvbe.1994.1003
Bullock, H. E., Harlow, L. L., \& Mulaik, S. A. (1994). Causation issues in structural equation modeling research. Structural Equation Modeling: A Multidisciplinary Journal, 1(3), 253-267. doi: 10.1080/10705519409539977

Byrne, B. M. (2010). Structural equation modeling with AMOS: Basic concepts, applications, and programming (2nd ed.). New York, NY: Routledge.

Cardenas, I. C., Voordijk, H., \& Dewulf, G. (2017). Beyond theory: Towards a probabilistic causation model to support project governance in infrastructure projects. International Journal of Project Management, 35(3), 432-450. doi: 10.1016/j.ijproman.2017.01.002

Carranza, G., Garcia, M., \& Sanchez, B. (2020). Activating inclusive growth in railway SMEs by workplace innovation. Transportation Research Interdisciplinary Perspectives, 7, 100193. doi: 10.1016/j.trip.2020.100193

Chan, I. Y. S., Liu, A. M. M., \& Fellows, R. (2014). Role of leadership in fostering an innovation climate in construction firms. Journal of Management in Engineering, 30(6), 1-7. doi: 10.1061/(ASCE)ME.19435479.0000271

Chanpariyavatevong, K., Wipulanusat, W., Champahom, T., Jomnonkwao, S., Chonsalasin, D., \& Ratanavaraha, V. (2021). Predicting airline customer loyalty by integrating structural equation modeling and Bayesian networks. Sustainability, 13(13), 7046.

Cheng, C.-F., Lai, M.-K., \& Wu, W.-Y. (2010). Exploring the impact of innovation strategy on R\&D employees' job satisfaction: A mathematical model and empirical research. Technovation, 30(7-8), 459-470. doi: 10.1016/j.technovation.2010.03.006

de Oliveira, M. A., Dalla Valentina, L. V. O., \& Possamai, O. (2012). Forecasting project performance considering the influence of leadership style on organizational agility. International Journal of Productivity and Performance Management, 61(6), 653-671. doi: 10.1108/17410401211249201

Demircioglu, M. A. (2018). Examining the effects of social media use on job satisfaction in the Australian Public Service: Testing self-determination theory. Public Performance \& Management Review, 41(2), 300-327. doi: 10.1080/15309576.2017.1400991

Demircioglu, M. A., \& Berman, E. (2019). Effects of the innovation climate on turnover intention in the Australian Public Service. The American Review of Public Administration, 49(5), 614-628. doi: 10.1177/0275074018808914

Dlamini, W. M. (2010). A Bayesian belief network analysis of factors influencing wildfire occurrence in Swaziland. Environmental Modelling \& Software, 25(2), 199-208. doi: 10.1016/j.envsoft.2009.08.002

Dubbelt, L., Demerouti, E., \& Rispens, S. (2019). The value of job crafting for work engagement, task performance, and career satisfaction: longitudinal and quasi-experimental evidence. European Journal of Work and Organizational Psychology, 28(3), 300-314. doi: 10.1080/1359432X.2019.1576632

Ekici, A., \& Ekici, S. O. (2016). A Bayesian network analysis of ethical behavior. Journal of Macromarketing, 36(1), 96-115. doi: 10.1177/0276146715607620

Engineer Australia. (2012). Submission to inquiry into the shortage of engineering and related employment skills. 
Barton: The Institution of Engineers Australia.

Fernandez, S., \& Pitts, D. W. (2011). Understanding employee motivation to innovate: Evidence from front line employees in United States federal agencies. Australian Journal of Public Administration, 70(2), 202222. doi: 10.1111/j.1467-8500.2011.00726.x

Fuster-Parra, P., García-Mas, A., Ponseti, F. J., Palou, P., \& Cruz, J. (2014). A Bayesian network to discover relationships between negative features in sport: a case study of teen players. Quality \& Quantity, 48(3), 1473-1491. doi: 10.1007/s11135-013-9848-y

García-Chas, R., Neira-Fontela, E., \& Varela-Neira, C. (2016). High-performance work systems and job satisfaction: a multilevel model. Journal of Managerial Psychology, 31(2), 451-466. doi: 10.1108/JMP-042013-0127

Greenhaus, J. H., Parasuraman, S., \& Wormley, W. M. (1990). Effects of race on organizational experiences, job performance evaluations, and career outcomes. Academy of Management Journal, 33(1), 64-86. doi: $10.2307 / 256352$

Gupta, S., \& Kim, H. W. (2008). Linking structural equation modeling to Bayesian networks: Decision support for customer retention in virtual communities. European Journal of Operational Research, 190(3), 818-833. doi: 10.1016/j.ejor.2007.05.054

Hair, J. F., Black, W. C., Babin, B. J., \& Anderson, R. E. (2010). Multivariate data analysis: A global perspective (7th ed.). Upper Saddle River, NJ: Prentice Hall.

Hall, D. T., \& Chandler, D. E. (2005). Psychological success: When the career is a calling. Journal of Organizational Behavior, 26(2), 155-176. doi: 10.1002/job.301

Hsu, C.-I., Shih, M.-L., Huang, B.-W., Lin, B.-Y., \& Lin, C.N. (2009). Predicting tourism loyalty using an integrated Bayesian network mechanism. Expert Systems with Applications, 36(9), 11760-11763. doi: 10.1016/j. eswa.2009.04.010

Iacobucci, D. (2009). Everything you always wanted to know about SEM (structural equations modeling) but were afraid to ask. Journal of Consumer Psychology, 19(4), 673-680. doi: 10.1016/j.jcps.2009.09.002

Karia, N., \& Abu Hassan Asaari Muhammad, H. (2019). Leadership attributes and their impact on work-related attitudes. International Journal of Productivity and Performance Management, 68(5), 903-919. doi: 10.1108/IJPPM-02-2018-0058

Kayakutlu, G., Daim, T., Kunt, M., Altay, A., \& Suharto, Y. (2017). Scenarios for regional waste management. Renewable and Sustainable Energy Reviews, 74(Supplement C), 1323-1335. doi: 10.1016/j.rser.2016.11.147

Kim, S., Eun, \& Chang, G. W. (2009). An empirical analysis of innovativeness in government: findings and implications. International Review of Administrative Sciences, 75(2), 293-310. doi: 10.1177/0020852309104177

Kim, S., \& Yoon, G. (2015). An innovation-driven culture in local government: Do senior manager's transformational leadership and the climate for creativity matter? Public Personnel Management, 44(2), 147168. doi: $10.1177 / 0091026014568896$

Kim, S. E., \& Lee, J. W. (2009). The impact of management capacity on government innovation in Korea: An em- pirical study. International Public Management Journal, 12(3), 345-369. doi: 10.1080/10967490903103334

Lauría, E. J. M., \& Duchessi, P. J. (2006). A Bayesian belief network for IT implementation decision support. Decision Support Systems, 42(3), 1573-1588. doi: 10.1016/j.dss.2006.01.003

Lei, P.-W., \& Wu, Q. (2007). Introduction to structural equation modeling: Issues and practical considerations. Educational Measurement: Issues and Practice, 26(3), 33-43. doi: 10.1111/j.1745-3992.2007.00099.x

Lester, C. (2019). Engineering a local skills shortage in Australia. Retrieved from https://www.goodeducation.com.au/engineering-a-local-skills-shortage-inaustralia/

Li, X., Zhang, Y., Guo, F., Gao, X., \& Wang, Y. (2018). Predicting the effect of land use and climate change on stream macroinvertebrates based on the linkage between structural equation modeling and bayesian network. Ecological Indicators, 85, 820-831. doi: 10.1016/j.ecolind.2017.11.044

Lounsbury, J. W., Steel, R. P., Gibson, L. W., \& Drost, A. W. (2008). Personality traits and career satisfaction of human resource professionals. Human Resource Development International, 11(4), 351-366. doi: $10.1080 / 13678860802261215$

Marcot, B. G. (2012). Metrics for evaluating performance and uncertainty of Bayesian network models. Ecological Modelling, 230, 50-62. doi: 10.1016/j.ecolmodel.2012.01.013

McAdam, R., Moffett, S., Hazlett, S. A., \& Shevlin, M. (2010). Developing a model of innovation implementation for UK SMEs: A path analysis and explanatory case analysis. International Small Business Journal, 28(3), 195-214. doi: 10.1177/0266242609360610

Menzel, H. C., Aaltio, I., \& Ulijn, J. M. (2007). On the way to creativity: Engineers as intrapreneurs in organizations. Technovation, 27(12), 732-743. doi: 10.1016/j. technovation.2007.05.004

Mohammadfam, I., Ghasemi, F., Kalatpour, O., \& Moghimbeigi, A. (2017). Constructing a Bayesian network model for improving safety behavior of employees at workplaces. Applied Ergonomics, 58, 35-47. doi: 10.1016/j.apergo.2016.05.006

Nair, S. L. S., Aston , J., \& Kozlovski, E. (2019). The relationship between organisational culture and the job satisfaction of IT sector's employees in contrasting economies. Forum Scientiae Oeconomia, 7(3), 77-88. doi: 10.23762/FSO_VOL7_NO3_6

Ng, T. W. H., Eby, L. T., Sorensen, K. L., \& Feldman, D. C. (2005). Predictors of objective and subjective career success: a meta-analysis. Personnel Psychology, 58(2), 367-408. doi: 10.1111/j.1744-6570.2005.00515.x

Ohunakin, F., Adeniji, A., \& Oludayo, O. (2018). Perception of frontline employees towards career growth opportunities: implications on turnover intention. Business: Theory and Practice, 19, 278-287. doi: 10.3846/ btp. 2018.28

Oke, A., Munshi, N., \& Walumbwa, F. O. (2009). The influence of leadership on innovation processes and activities. Organizational Dynamics, 38(1), 64-72. doi: 10.1016/j.orgdyn.2008.10.005 
Orazi, D. C., Turrini, A., \& Valotti, G. (2013). Public sector leadership: new perspectives for research and practice. International Review of Administrative Sciences, 79(3), 486-504. doi: 10.1177/0020852313489945

Panuwatwanich, K., Stewart, R. A., \& Mohamed, S. (2008). The role of climate for innovation in enhancing business performance: The case of design firms. Engineering, Construction and Architectural Management, 15(5), 407-422. doi: 10.1108/09699980810902712

Parry, K., \& Proctor-Thomson, S. (2002). Leadership, culture and performance: The case of the New Zealand public sector. Journal of Change Management, 3(4), 376-399. doi: 10.1080/714023843

Peluchette, J. V. E. (1993). Subjective career success: The influence of individual difference, family, and organizational variables. Journal of Vocational Behavior, 43(2), 198-208. doi: 10.1006/jvbe.1993.1042

Pot, F. (2011). Workplace innovation for better jobs and performance. International Journal of Productivity and Performance Management, 60(4), 404-415. doi: 10.1108/17410401111123562

Sarros, J. C., Cooper, B. K., \& Santora, J. C. (2008). Building a climate for innovation through transformational leadership and organizational culture. Journal of Leadership \& Organizational Studies, 15(2), 145-158. doi: $10.1177 / 1548051808324100$

Seibert, S. E., \& Kraimer, M. L. (2001). The five-factor model of personality and career success. Journal of Vocational Behavior, 58(1), 1-21. doi: 10.1006/ jvbe.2000.1757

Solís, M., \& Mora-Esquivel, R. (2019). Development and validation of a measurement scale of the innovative culture in work teams. International Journal of Innovation Science, 11(2), 299-322. doi: 10.1108/IJIS-072018-0073

Tobing, D. S. K. (2016). The effect of compensation, career development, work-family support on job satisfaction. Polish Journal of Management Studies, 14(1), 206-213. doi: 10.17512/pjms.2016.14.1.19

Totterdill, P., \& Exton, R. (2014). Defining workplace innovation. Strategic Direction, 30(9), 12-16. doi: 10.1108/ SD-09-2014-0112

van Horn, J. E., Reinders, M., Eisenberg, M. J., de LimaHeijns, A., \& Posthumus, J. (2016). Using structural equation modeling to assess the impact of factors on sexual risk and delinquent behavior in Dutch female offenders. Children and Youth Services Review, 71, 233-240. doi: 10.1016/j.childyouth.2016.11.023

Weston, R., \& Paul, A. G. J. (2006). A Brief guide to structural equation modeling. The Counseling Psychologist, 34(5), 719-751. doi: doi: 10.1177/0011000006286345

Williamson, J. M., Lounsbury, J. W., \& Han, L. D. (2013). Key personality traits of engineers for innovation and technology development. Journal of Engineering and Technology Management, 30(2), 157-168. doi: 10.1016/j.jengtecman.2013.01.003

Wipulanusat, W., Panuwatwanich, K., \& Stewart, R. A. (2017). Statistical data analysis of culture for innovation using an open data set from the Australian Public Service. Lecture Notes in Computer Science, 10365, 78-89. doi: 10.1007/978-3-319-60795-5_7
Wipulanusat, W., Panuwatwanich, K., \& Stewart, R. A. (2018). Pathways to workplace innovation and career satisfaction in the public service: The role of leadership and culture. International Journal of Organizational Analysis, 26(5), 890-914. doi: 10.1108/IJOA03-2018-1376

Wipulanusat, W., Panuwatwanich, K., Stewart, R. A., Arnold, S. L., \& Wang, J. (2020). Bayesian network revealing pathways to workplace innovation and career satisfaction in the public service. Journal of Management Analytics, 7(2), 253-280. doi: 10.1080/23270012.2020.1749900

Wipulanusat, W., Panuwatwanich, K., Stewart, R. A., Parnphumeesup, P., \& Sunkpho, J. (2020). Unraveling key drivers for engineer creativity and meaningfulness of work: Bayesian network approach. Management and Production Engineering Review, 11(2), 26-37. doi: 10.24425/mper.2020.133726

Wipulanusat, W., Panuwatwanich, K., Stewart, R. A., \& Sunkpho, J. (2019). Drivers and barriers to innovation in the Australian public service: a qualitative thematic analysis. Engineering Management in Production and Services, 11(1), 7-22.

Wipulanusat, W., Panuwatwanich, K., Stewart, R. A., \& Sunkpho, J. (2020). Applying mixed methods sequential explanatory design to innovation management. Lecture Notes in Mechanical Engineering, 485495.

Wipulanusat, W., Sunkpho, J., \& Stewart, R. A. (2021). Effect of cross-departmental collaboration on performance: Evidence from the Federal Highway Administration. Sustainability, 13(11), 6024. doi: 10.3390/ su13116024

Wu, W. W. (2010). Linking Bayesian networks and PLS path modeling for causal analysis. Expert Systems with Applications, 37(1), 134-139. doi: 10.1016/j. eswa.2009.05.021

Yates, A. (2001). Raising the status of engineers. Barton, ACT: Institution of Engineers.

Yates, A. (2012). The challenges for agencies in maintaining in-house engineering professional staff. In Engineer Australia (Ed.), Government as an informed buyer: How the public sector can most effectively procure engineering-intensive products and services (pp. 70-79). Barton, A.C.T. 